\title{
MODEL SENTRALISASI DUAL CHANNEL SUPPLY CHAIN UNTUK SATU PEMANUFAKTUR DAN DUA PENGECER DENGAN KOMPETISI HARGA DISKON
}

\section{THE CENTRALIZED DUAL CHANNEL SUPPLY CHAIN MODEL FOR ONE MANUFACTURER AND TWO RETAILERS WITH DISCOUNT PRICE COMPETITION}

\author{
Diah Nur Hidayatia ${ }^{a}$ Ririn Setiyowati ${ }^{\text {b }}$, Pangadi \\ Program Studi Matematika FMIPA UNS \\ J1. Ir. Sutarmi No. 36A, Kentingan, Jebres, Surakarta \\ adiahnurh@student.uns.ac.id, ${ }^{b}$ ririnsetiyowati@staff.uns.ac.id, \\ cpangadi_adi@staff.uns.ac.id
}

\begin{abstract}
ABSTRAK
Perkembangan bisnis online yang pesat seperti di era sekarang ini membuka peluang yang sangat besar bagi pemanufaktur untuk menjual produk ke konsumen secara langsung dengan melalui media online. Biasanya pemanufaktur hanya menjual produk kepada pengecer, kemudian pengecer menjual kembali produk tersebut kepada konsumen dengan melalui media offline. Pada penelitian ini akan dikembangkan model sentralisasi dual channel supply chain dengan kompetisi harga diskon. Tujuan dari penelitian ini adalah untuk mengonstruksi dan menentukan fungsi keuntungan optimal dari satu pemanufaktur dan dua pengecer dengan kompetisi harga diskon. Model yang dikonstruksi merupakan fungsi keuntungan terhadap tiga variabel keputusan tanpa kendala dengan menggunakan sistem sentralisasi. Tiga variabel keputusan yang ditentukan yaitu harga jual media online, harga jual pengecer 1, dan harga jual pengecer 2. Setelah ditentukan penyelesaian optimalnya kemudian menganalisis efek dari kompetisi harga diskon yang diberikan. Hasil yang didapat pada penelitian ini menunjukkan bahwa kompetisi harga diskon dapat meningkatkan keuntungan pada keseluruhan sistem sentralisasi.
\end{abstract}

Kata Kunci : DCSC, harga diskon, offlline, online, sistem sentralisasi.

\begin{abstract}
E-commerce rapid development in this era is resulting a high probability to manufactures for sell their products toward customers directly in online media. Usually, manufactures only sell products to retailers, then retailers resell these products to consumers through offline media. This research will develop a dual channel supply chain centralization model with discounted price competition. The purpose of this research is to construct and determine the optimal profit function of one manufacturer and two retailers at a discounted price competition. The constructed model is a profit function of three decision variables without constraints using a centralized system. Three decision variables are determined namely selling price of online media, selling price of retailer 1 , and selling price of retailer 2. After the optimal profit is determined, then analyzing the effect of discount price competition is given. The results obtained in this research indicate that discounted price competition can increase profits in the whole centralized system.
\end{abstract}

Kata Kunci : DCSC, discount price, offlline, online, centralized system. 


\section{Pendahuluan}

Model persediaan supply chain (SC) merupakan salah satu contoh model matematika yang sering digunakan dalam bidang ekonomi industri. Menurut Kumar dan Kumar (2013), SC adalah sistem yang mencakup serangkaian proses dari produksi sampai penjualan produk ke konsumen. SC terbagi menjadi dua yaitu single channel supply chain (SCSC) dan dual channel supply chain (DCSC). SCSC menggunakan satu media dalam penjualan yaitu media offline yang mana terjadi tatap muka langsung antara penjual dan pembeli sehingga memperoleh kesepakatan. Sedangkan menurut Widodo et al. (2011), suatu penjualan dikatakan menganut konsep DCSC jika kedua media penjualan beroperasi secara bersama-sama (offline dan online). Harga dan biaya layanan menjadi salah satu faktor yang memengaruhi konsumen dalam memilih media penjualan.

Dumrongsiri et al. (2008) meneliti model dengan asumsi konsumen peka terhadap harga dan kualitas layanan. Menurut Grewal et al. (1998), untuk dapat mempertahankan keseimbangan angka penjualan perlu diunggulkan tiga hal yaitu, store reputation, brand name, dan diskon. Cai et al. (2009) meneliti efek dari berbagai kontrak harga diskon dan skema harga pada rantai pasokan yang menunjukkan bahwa kontrak harga diskon sederhana bisa meningkatkan kinerja seluruh rantai pasokan.

Rofin dan Mahanty (2017) membahas masalah struktur rantai pasokan produsen yang dihadapkan pada tiga pilihan media penjualan, yaitu retailer-e-tailer, company store-e-tailer, dan retailer-e-marketplace dengan kecenderungan konsumen yang berbeda-beda pada media penjualan online. Setiyowati et al. (2019) meneliti tentang Dual Channel Closed-Loop Supply Chain dengan memertimbangkan kontrak harga diskon dan waktu tunggu. Berdasarkan pada penelitian terkait DCSC dan kontrak harga diskon, artikel ini berfokus pada struktur rantai pasokan dengan sistem sentralisasi DCSC untuk satu pemanufaktur dan dua pengecer dengan kompetisi harga diskon.

\section{Metode Penelitian}

Metode yang digunakan dalam penelitian ini adalah studi literatur. Literatur yang digunakan meliputi buku dan jurnal tentang Dual Channel Supply Chain, kemudian dibuat pengembangan model dan dianalisis pengaruh harga diskon terhadap penyelesaian optimalnya. Berikut langkah operasional yang digunakan dalam penelitian ini. 
(1) Mempelajari penelitian terdahulu mengenai model DCSC.

(2) Menentukan asumsi model DCSC yang akan dikembangkan.

(3) Menentukan fungsi tujuan yang berupa fungsi keuntungan sistem dari satu pemanufaktur dan dua pengecer.

(4) Membuktikan model memiliki titik global maksimum.

(5) Menentukan harga jual pemanufaktur dan kedua pengecer.

(6) Mencari nilai parameter yang sesuai, kemudian diterapkan kedalam model yang diperoleh, lalu menentukan penyelesaian optimalnya.

(7) Mengubah nilai parameter untuk menganalisis sensitivitas parameter terhadap keuntungan sistem pada hasil penerapan model.

\section{Hasil dan Pembahasan}

\section{Kerangka Model}

Model dual channel supply chain (DCSC) terdiri dari satu pemanufaktur dan dua pengecer. Pemanufaktur menjual produk ke pengecer 1 dan pengecer 2 berturut-turut dengan harga $w_{1}$ dan $w_{2}$ melalui media offline serta menjual produk secara langsung ke konsumen dengan harga $p_{m}$ melalui media online. Pengecer 1 dan pengecer 2 menjual produk ke konsumen berturut-turut dengan harga $p_{1}$ dan $p_{2}$ melalui media offline. Alur dari model DCSC ditunjukkan pada Gambar 1.

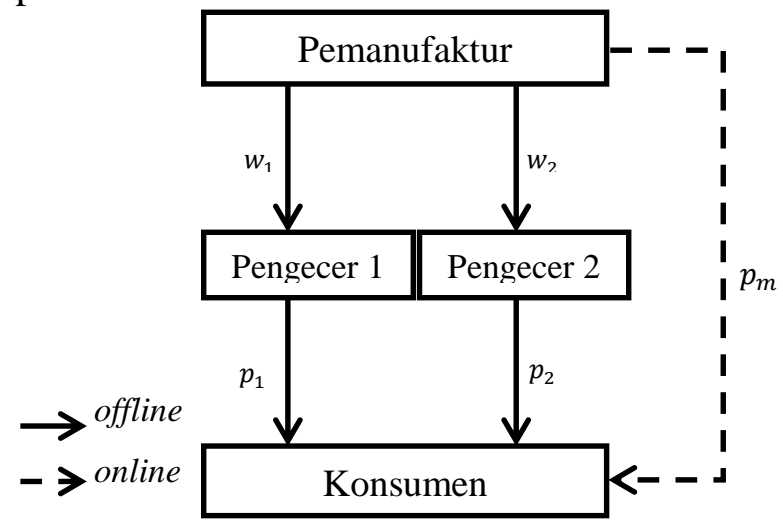

Gambar 1. Alur model DCSC

Notasi yang digunakan dalam model dijelaskan pada Tabel 1.

Tabel 1. Notasi

\begin{tabular}{cl}
\hline Proporsi & Keterangan \\
\hline$\theta$ & Proporsi antarmedia \\
\hline Parameter & Proporsi antarpengecer \\
Permintaan & \\
\hline$a$ & Permintaan dasar konsumen \\
$D_{o}$ & Permintaan media online \\
$D_{1}$ & Permintaan pengecer 1 \\
$D_{2}$ & Permintaan pengecer 2 \\
$w_{1,2}$ & Harga grosir pengecer 1 dan 2 \\
$c_{m}$ & Biaya produksi \\
$c_{r}$ & Biaya operasional pengecer \\
$l$ & Waktu tunggu pengiriman \\
$\delta_{1,2}$ & Sensitivitas harga silang antara \\
& media online dan offline pada \\
& pengecer 1 dan 2 \\
$\beta_{1,2}$ & Elastisitas permintaan pengecer 1 \\
$\beta_{3}$ & dan 2 Elastisitas permintaan media online \\
&
\end{tabular}


Variabel

Keputusan

\begin{tabular}{cl}
\hline$p_{m}$ & Harga jual media online \\
$p_{1}$ & Harga jual pengecer 1 \\
$p_{2}$ & Harga jual pengecer 2 \\
\hline
\end{tabular}

Asumsi yang digunakan untuk

mengkonstruksi model sebagai berikut.

(1) Terdiri dari satu pemanufaktur dan dua pengecer untuk produk yang sama.

(2) Pemanufaktur menjual produk secara online kepada konsumen dengan harga $p_{m}$ dan secara offline kepada pengecer 1 dan pengecer 2 dengan harga $w_{1}$ dan $w_{2}$.

(3) Pengecer 1 dan pengecer 2 menjual produk secara offline ke konsumen dengan harga $p_{1}$ dan $p_{2}, p_{1}, p_{2}>w_{1}, w_{2}$.

(4) Pemanufaktur memberikan kontrak harga diskon kepada kedua pengecer yaitu harga grosir $w_{1}$ dan $w_{2}$ selalu lebih kecil dari pada harga jual online $p_{m}$.

(5) Diasumsikan bahwa nilai elastisitas selalu lebih besar dari nilai sensitivitas, $\min \left\{\beta_{1}, \beta_{2}, \beta_{3}\right\}>\max \left\{\delta_{1}, \delta_{2}\right\}$.

(6) Semua nilai parameter positif.

\section{Konstruksi Model}

\section{Fungsi Permintaan}

Berdasarkan deskripsi, notasi, dan asumsi yang telah dijelaskan akan dikonstruksikan fungsi permintaan pengecer 1, pengecer 2, dan pemanufaktur. Jumlah proporsi awal antara media online dan offline yaitu 1. Jika proporsi media offline sebesar $\theta$ maka proporsi media online yaitu $(1-\theta)$. Permintaan media offline terdiri dari permintaan pengecer 1 dan pengecer 2. Jika proporsi pengecer 1 adalah $\alpha$, maka proporsi pengecer 2 yaitu $(1-\alpha)$. Fungsi permintaan linear dengan elastisitas $\beta_{1}, \beta_{2}$ secara berturut-turut pada pengecer 1 dan 2 (media offline), dan $\beta_{3}$ pada media online. Fungsi permintaan juga linear terhadap sensitivitas harga silang antara media offline dan online. Selain itu, bahwa fungsi permintaan linear dengan sensitivitas waktu tunggu yang dinotasikan $\gamma_{1}$ dan $\gamma_{2}$. Semakin lama waktu tunggu akan memengaruhi prioritas konsumen untuk berpindah dari media online ke media offline. Waktu tunggu dinotasikan dengan $l$. Fungsi permintaan media offline terdiri dari pengecer 1 dan pengecer 2 yang dinotasikan secara berturut-turut yaitu $D_{1}$ dan $D_{2}$. Kemudian untuk fungsi keuntungan media online dinotasikan dengan $D_{o}$. Sehingga fungsi permintaan pada pengecer 1 , pengecer 2 , dan pemanufaktur dirumuskan sebagai berikut:

$$
\begin{aligned}
D_{1}= & \theta \alpha a-\beta_{1} p_{1}+\delta_{1} p_{m}+\gamma_{1} l \\
D_{2}= & \theta(1-\alpha) a-\beta_{2} p_{2}+\delta_{2} p_{m}+\gamma_{2} l \\
D_{o}= & a(1-\theta)-\beta_{3} p_{m}+\delta_{1} p_{1}+\delta_{2} p_{2}-\left(\gamma_{1}+\right. \\
& \left.\gamma_{2}\right) l
\end{aligned}
$$

dengan $p_{1}$ harga per unit pada pengecer 1 dan $p_{2}$ harga per unit pada pengecer 2 pada 
media offline. Harga per unit pada media online yaitu $p_{m}$ sudah termasuk biaya operasional dan biaya pengiriman.

\section{Fungsi Keuntungan}

Fungsi keuntungan pengecer 1 diperoleh dari total pendapatan pengecer 1 yaitu harga jual pengecer $1 p_{1}$ dikalikan dengan persamaan (1) diperoleh $p_{1} D_{1}$. Kemudian dikurangi dengan total pengeluaran pengecer 1 yaitu harga grosir $w_{1}$ dan biaya operasional pengecer sebesar $c_{r}$, keduanya dikalikan dengan persamaan (1). Pada model ini diperhatikan kontrak harga diskon dari pemanufaktur ke pengecer 1 sehingga harga grosir $w_{1}$ menjadi $w_{1}=\lambda_{1} p_{m}$. Sehingga diperoleh fungsi keuntungan pengecer 1 yaitu

$$
\pi_{1}=\left(p_{1}-\lambda_{1} p_{m}-c_{r}\right) D_{1} .
$$

Fungsi keuntungan pengecer 2 diperoleh dari total pendapatan pengecer 2 yaitu harga jual pengecer $2 p_{2}$ dikalikan dengan persamaan (2) diperoleh $p_{2} D_{2}$. Kemudian dikurangi dengan total pengeluaran pengecer 2 yaitu harga grosir $w_{2}$ dan biaya operasional pengecer sebesar $c_{r}$, keduanya dikalikan dengan persamaan (2). Pada model ini diperhatikan kontrak harga diskon dari pemanufaktur ke pengecer 2 sehingga harga grosir $w_{2}$ menjadi $w_{2}=\lambda_{2} p_{m}$. Sehingga diperoleh fungsi keuntungan pengecer 2 yaitu

$$
\pi_{2}=\left(p_{2}-\lambda_{2} p_{m}-c_{r}\right) D_{2} \text {. }
$$

Fungsi keuntungan pemanufaktur diperoleh dari total pendapatan pemanufaktur yaitu harga grosir $w_{1}=\lambda_{1} p_{m}$ dikalikan dengan persamaan (1) diperoleh $\lambda_{1} p_{m} D_{1}$ ditambah harga grosir $w_{2}=\lambda_{2} p_{m}$ dikalikan dengan persamaan (2) diperoleh $\lambda_{2} p_{m} D_{2}$ ditambah harga jual media online $p_{m}$ dikalikan dengan persamaan (3) diperoleh $p_{m} D_{o}$. Kemudian dikurangi dengan total pengeluaran pemanufaktur yaitu biaya produksi produk dikalikan dengan persamaan (1), (2), dan (3). Sehingga diperoleh fungsi keuntungan pemanufaktur yaitu

$$
\begin{aligned}
\pi_{o}= & \lambda_{1} p_{m} D_{1}+\lambda_{2} p_{m} D_{2}+p_{m} D_{o}- \\
& c_{m}\left(D_{1}+D_{2}+D_{o}\right) .
\end{aligned}
$$

\section{Model Sentralisasi DCSC}

Model sentralisasi DCSC merupakan fungsi keuntungan sistem nonlinear tanpa kendala yang diperoleh dari penjumlahan persamaan (4), (5), dan (6) yaitu

$$
\begin{aligned}
& \pi_{c}=\left(p_{1}-\lambda_{1} p_{m}-c_{r}\right) D_{1}+\left(p_{2}-\lambda_{2} p_{m}-\right. \\
& \left.c_{r}\right) D_{2}+\lambda_{1} p_{m} D_{1}+\lambda_{2} p_{m} D_{2}+p_{m} D_{o}- \\
& c_{m}\left(D_{1}+D_{2}+D_{o}\right) .
\end{aligned}
$$

\section{Solusi Optimal}

Pada persamaan (7), dapat dikonstruksikan matriks Hessian yang diperoleh dari turunan parsial kedua persamaan (7) terhadap $p_{1}, p_{2}$, dan $p_{m}$ yaitu 
$H=\left[\begin{array}{ccc}-2 \beta_{1} & 0 & 2 \delta_{1} \\ 0 & -2 \beta_{2} & 2 \delta_{2} \\ 2 \delta_{1} & 2 \delta_{2} & -2 \beta_{3}\end{array}\right] \quad$ sedemikian sehingga diperoleh principal minor determinant dari matriks Hessian tersebut yaitu $H_{11}=-2 \beta_{1}$ bernilai negatif, $H_{22}=$ $4 \beta_{1} \beta_{2}$ bernilai positif, dan $H_{33}=-8 \beta_{1} \beta_{2} \beta_{3}+$ $8 \beta_{1} \delta_{1}{ }^{2}+8 \beta_{2} \delta_{2}{ }^{2}$ bernilai negatif. Hal tersebut menunjukan bahwa persamaan merupakan fungsi konkaf tegas. Selanjutnya akan dicari penyelesaian optimal dari fungsi tersebut dengan cara menentukan turunan pertama dari persamaan (7) terhadap $p_{1}$, $p_{2}$, dan $p_{m}$ kemudian dibuat sama dengan nol

$$
\frac{\partial \pi_{c}}{\partial p_{1}}=0, \quad \frac{\partial \pi_{c}}{\partial p_{1}}=0, \text { dan } \frac{\partial \pi_{c}}{\partial p_{1}}=0 .
$$

Sistem persamaan linier tersebut diselesaikan dengan menggunakan bantuan software Mathematica sehingga diperoleh solusi optimal yaitu

$$
\begin{aligned}
\boldsymbol{p}_{1}{ }^{*}= & \left(c_{r} \beta_{1} \beta_{2} \beta_{3}+\beta_{2} \beta_{3} \gamma_{1} l+a \beta_{2} \delta_{1}-\right. \\
& \beta_{2} \delta_{1} \gamma_{1} l-\beta_{2} \delta_{1} \gamma_{2} l-c_{r} \beta_{2} \delta_{1}{ }^{2}+ \\
& \delta_{1} \delta_{2} \gamma_{2} l-c_{r} \beta_{1} \delta_{2}{ }^{2}-\delta_{2}{ }^{2} \gamma_{1} l+ \\
& c_{m}\left(\beta_{1} \beta_{2} \beta_{3}-\beta_{2} \delta_{1}{ }^{2}-\beta_{1} \delta_{2}{ }^{2}\right)+ \\
& a\left(\delta_{1}\left(-\beta_{2}+\delta_{2}\right)+\alpha\left(\beta_{2} \beta_{3}-\delta_{2}\left(\delta_{1}+\right.\right.\right. \\
& \left.\left.\left.\left.\delta_{2}\right)\right)\right) \theta\right) /\left(2 \beta_{1} \beta_{2} \beta_{3}-2 \beta_{2} \delta_{1}{ }^{2}-2 \beta_{1} \delta_{2}{ }^{2}\right)
\end{aligned}
$$

$\boldsymbol{p}_{\mathbf{2}}{ }^{*}=\left(c_{r} \beta_{1} \beta_{2} \beta_{3}+\beta_{1} \beta_{3} \gamma_{2} l-c_{r} \beta_{2} \delta_{1}{ }^{2}-\right.$

$\delta_{1}^{2} \gamma_{2} l+a \beta_{1} \delta_{2}-\beta_{1} \delta_{2} \gamma_{1} l-\beta_{1} \delta_{2} \gamma_{2} l+$

$\delta_{1} \delta_{2} \gamma_{1} l-c_{r} \beta_{1} \delta_{2}{ }^{2}+c_{m}\left(\beta_{1} \beta_{2} \beta_{3}-\beta_{2} \delta_{1}{ }^{2}-\right.$

$\left.\beta_{1} \delta_{2}{ }^{2}\right)+a\left(-\beta_{1}\left((-1+\alpha) \beta_{3}+\delta_{2}\right)+\right.$

$\left.\left.\delta_{1}\left((-1+\alpha) \delta_{1}+\alpha \delta_{2}\right)\right) \theta\right) /\left(2 \beta_{1} \beta_{2} \beta_{3}-\right.$

$\left.2 \beta_{2}{\delta_{1}}^{2}-2 \beta_{1}{\delta_{2}}^{2}\right)$

$$
\begin{aligned}
& \boldsymbol{p}_{\boldsymbol{m}}{ }^{*}=\left(\beta _ { 2 } \left(-l \beta_{1}\left(\gamma_{1}+\gamma_{2}\right)+l \gamma_{1} \delta_{1}+\right.\right. \\
& \left.\mathrm{c}_{m}\left(\beta_{1} \beta_{3}-\delta_{1}{ }^{2}\right)\right)+l \beta_{1} \gamma_{2} \delta_{2}-\mathrm{c}_{m} \beta_{1} \delta_{2}{ }^{2}+ \\
& a\left(\alpha \beta_{2} \delta_{1} \theta+\beta_{1}\left(\beta_{2}-\left(\beta_{2}+(-1+\right.\right.\right. \\
& \left.\left.\left.\left.\alpha) \delta_{2}\right) \theta\right)\right)\right) /\left(2 \beta_{1} \beta_{2} \beta_{3}-2 \beta_{2} \delta_{1}{ }^{2}-2 \beta_{1} \delta_{2}{ }^{2}\right) .
\end{aligned}
$$

\begin{tabular}{|c|c|c|}
\hline Parameter & Nilai & Satuan \\
\hline$a$ & 100 & (unit/tahun) \\
\hline$\beta_{1}$ & 0.4 & (unit ${ }^{2} / \$ /$ tahun) \\
\hline$\beta_{2}$ & 0.3 & (unit ${ }^{2} / \$ /$ tahun) \\
\hline$\beta_{3}$ & 0.2 & (unit ${ }^{2} / \$ /$ tahun) \\
\hline$\delta_{1}$ & 0.075 & (unit/\$) \\
\hline$\delta_{2}$ & 0.075 & (unit/ \$) \\
\hline$\gamma_{1}$ & 0.3 & (unit/ \$) \\
\hline$\gamma_{2}$ & 0.4 & (unit/ \$) \\
\hline$l$ & 5 & (hari) \\
\hline $\mathrm{c}_{r}$ & 3 & (\$/unit) \\
\hline $\mathrm{c}_{m}$ & 15 & (\$/unit) \\
\hline$\theta$ & 0.6 & - \\
\hline$\alpha$ & 0.4 & - \\
\hline$\lambda_{1}$ & 46 & $(\%)$ \\
\hline$\lambda_{2}$ & 61 & $(\%)$ \\
\hline
\end{tabular}

\section{Simulasi Numerik}

Simulasi numerik digunakan untuk meggambarkan perilaku model DCSC dengan sistem sentralisasi. Kemudian menyelidiki efek dari kompetisi harga diskon dan waktu tunggu pada media online. Nilai parameter yang digunakan dalam simulasi numerik ditunjukkan pada Tabel 2 dan hasil dari simulasi tertera pada Tabel 3.

Tabel 2. Nilai parameter 
Tabel 3. Hasil Simulasi

\begin{tabular}{|c|c|c|}
\hline $\begin{array}{l}\text { Variabel } \\
\text { Keputusan }\end{array}$ & $\begin{array}{l}\text { Sentralisasi } \\
\text { Tanpa } \\
\text { Kompetisi } \\
\text { Harga } \\
\text { Diskon }\end{array}$ & $\begin{array}{l}\text { Sentralisasi } \\
\text { dengan } \\
\text { Kompetisi } \\
\text { Harga } \\
\text { Diskon }\end{array}$ \\
\hline$p_{1}$ & 78.50 & 76.64 \\
\hline$p_{2}$ & 102.51 & 100.02 \\
\hline$p_{m}$ & 134.88 & 158.24 \\
\hline
\end{tabular}

\begin{tabular}{lll}
\hline $\begin{array}{l}\text { Keuntungan } \\
\text { Optimal }\end{array}$ & & \\
\hline $\begin{array}{l}\text { Keuntungan } \\
\text { Pengecer } 1\end{array}$ & 6.98 & 10.75 \\
$\begin{array}{l}\text { Keuntungan } \\
\text { Pengecer 2 }\end{array}$ & 352.06 & 6.78 \\
$\begin{array}{l}\text { Keuntungan } \\
\text { Pemanufaktur }\end{array}$ & 3674.56 & 4457.71 \\
$\begin{array}{l}\text { Keuntungan } \\
\text { Sistem }\end{array}$ & 4033.61 & 4475.25 \\
\hline
\end{tabular}

Berdasarkan hasil simulasi pada Tabel

3, terlihat bahwa keuntungan sistem yang paling optimal diperoleh ketika menggunakan sistem sentralisasi dengan kompetisi harga diskon yaitu 4475.25. Keuntungan optimal diperoleh ketika harga pengecer 1 adalah 76.64, harga pengecer 2 adalah 100.02, dan harga jual online adalaha 158.24 .

\section{Analisis Sensitivitas}

Parameter yang akan dianalisis pada artikel ini yaitu waktu tunggu pengiriman barang dengan nilai parameter di interval $[2,6]$.
Tabel 4. Analisis sensitivitas $l$ tanpa kontrak harga diskon

\begin{tabular}{|c|c|c|c|c|c|c|c|}
\hline$l$ & $p_{1}$ & $p_{2}$ & $p_{m}$ & $\Pi_{1}$ & $\Pi_{2}$ & $\Pi_{o}$ & $\Pi_{c}$ \\
\hline 2 & $78.2^{\prime}$ & 101.7: & 139.7 & 4.23 & 355.0 ? & 3687.5 & 4046.87 \\
\hline 3 & 78.31 & 101.9 & 138.1: & 5.17 & $354.1\}$ & $3684.3 !$ & 4043.7 \\
\hline 4 & 78.4: & 102.2 ! & 136.5 & 6.08 & 353.1: & 3680.0: & : 4039.2 \\
\hline 5 & 78.5 & 102.5 & 134.88 & 6.98 & $352.0 t$ & 3674.5 & 4033.61 \\
\hline 6 & $78.5^{\prime}$ & 102.7: & $133.2 !$ & 7.85 & $350.8^{2}$ & 3667.91 & 4026. \\
\hline
\end{tabular}
online $\left(p_{m}\right)$ akan berkurang ketika waktu tunggu pengiriman barang semakin lama. Hal tersebut juga berpengaruh pada keuntungan optimal pada sistem yang juga menurun.

Tabel 5. Analisis sensitivitas $l$ dengan kontrak harga diskon

\begin{tabular}{|c|c|c|c|c|c|c|c|}
\hline l & $p_{1}$ & $p_{2}$ & $p_{m}$ & $\Pi_{1}$ & $\Pi_{2}$ & $\Pi_{o}$ & $\Pi_{c}$ \\
\hline 2 & $76.4 i$ & 99.23 & 163.1: & -19.7 & -43.3 & 4693.6 & 4630 \\
\hline 3 & 76.5 & 99.5 & 161.5 & -9.8 & -27.1 & 4614.4 & 4577.5 \\
\hline 4 & $76.5:$ & 99.76 & 159.8: & 0.35 & -10.4 & 4535.8: & 4525.7 \\
\hline 5 & $76.6^{4}$ & 100.0 & 158.2 & 10.75 & 6.78 & 4457.7 & 4475.2 \\
\hline 6 & 76.7: & 100.2 & 156.6: & 21.4 & 24.48 & 4380.1: & 4426. \\
\hline \multicolumn{8}{|c|}{$\begin{array}{l}\text { Terlihat bahwa pada Tabel 5, harga jual } \\
\text { online }\left(p_{m}\right) \text { akan berkurang ketika waktu } \\
\text { tunggu pengiriman barang semakin lama. } \\
\text { Hal tersebut juga berpengaruh pada }\end{array}$} \\
\hline
\end{tabular}


menurun. Batas waktu tunggu pengiriman barang agar tidak ada anggota pada sistem yang mengalami kerugian yaitu 5 hari.

\section{Kesimpulan}

Pada artikel ini, mengembangkan model sentralisasi dual channel supply chain untuk satu pemanufaktur dan dua pengecer dengan kompetisi harga diskon. Berdasarkan dari hasil penelitian dan simulasi numerik yang dilakukan dapat disimpulkan bahwa sistem sentralisasi dengan kompetisi harga diskon lebih menguntungkan dari pada sistem sentralisasi tanpa kontrak harga diskon.

Selain itu waktu tunggu pengiriman barang pada media online juga berpengaruh pada hasil keuntungan optimal sistem. Semakin lama waktu tunggu pengiriman barang, maka semakin menurun pula keuntungan optimal pada sistem.

\section{Ucapan Terimakasih}

Terima kasih kepada Bu Ririn dan Pak Pangadi sebagai dosen pembimbing yang telah membantu dalam kegiatan penelitian yang dilakukan.

\section{Pustaka}

Cai, G. (George), Zhang, Z. G., \& Zhang, M. 2009, Game theoretical perspectives on dual-channel supply chain competition with price discounts and pricing schemes, International Journal of Production Economics, 117(1) : 80-96.

Dumrongsiri, A., Fan, M., Jain, A., \& Moinzadeh, K. 2008, A supply chain model with direct and retail channels. European Journal of Operational Research, 187(3) : 691-718.

Grewal, D., R. Krishnan, J. Baker, \& N. Borin, 1998, The Effect of Store Name, Brand Name, and Price Discounts on Consumers Evaluation and Purchase Intention. Journal of Retailing, 74(3) : 331-352.

Kumar, N. R., \& Satheesh Kumar, R. M. 2013, Closed Loop Supply Chain Management and Reverse LogisticsA Literature Review. International Journal of Engineering Research and Technology, 6(4) : 974-3154.

Rofin, T. M. \& B. Mahanty, 2017, Optimal Dual-Channel Supply Chain Configuration for Product Categories with Different Customer Preference of Online Channel. Springer Science Business Media, LLC.

Setiyowati, R., Sutanto, S. N. P. Ramadhani, \& P. Widyaningsih, 2019, Dual channel closed-loop supply chain model with one manufacturer and 
two retailers under price discount contract and delivery lead time. AIP

Conference Proceedings, 2192 , 060019.

Widodo, E., K. Takahashi, K. Morikawa, I.N. Pujawan, \& B. Santosa. 2011, Managing Sales Return in Dual Sales Channel: Its Product Substitution and Return Channel Analysis. Internasional Journal of Industrial and System Engeneering, 9(2) : 121149. 
